\title{
Auge e declínio da hipótese dos mercados eficientes ${ }^{1}$
}

\author{
Height and decay of the hypotheses of efficient markets
}

\author{
LUIZ ANTÔNIO DE OLIVEIRA LIMA*
}

\begin{abstract}
RESUMO: Eugene Fama define um mercado como eficiente se refletir totalmente as informações existentes sobre os valores fundamentais de um ativo financeiro. De acordo com essa hipótese, esse tipo de mercado coloca à disposição dos agentes as opções ótimas para investir seu dinheiro, levando a uma alocação eficiente de capital. O objetivo deste artigo é mostrar que essa condição de fato não existe na realidade econômica e, como consequência, discutir como as formas alternativas de mercado de ativos norteiam o processo de investimento. As formas alternativas de alocação implicam que os agentes econômicos não seguem o modelo ideal de "racionalidade plena", mas seguem uma "forma fraca" consistente com as decisões que devem ser tomadas em condições de incerteza. Essa análise nos permitirá construir modelos mais realistas de mercados financeiros, considerando não apenas suas condições de normalidade, mas também as circunstâncias que explicam sua instabilidade e crises.
\end{abstract}

PALAVRAS-CHAVE: Mercados eficientes; mercados financeiros.

ABSTRACT: Eugene Fama defines a market as efficient if it fully reflects the existing information about the fundamental values of a financial asset. According to this hypothesis this kind of market makes available to the agents the optimal options for investing their money, leading in consequence to an efficient allocation of capital. The aim of this article is to show that this condition in fact does not exist in economic reality and as consequence to discuss how the alternative forms of asset markets guide the process of investment. The alternative forms of allocation imply that economic agents do not follow the ideal model of "full rationality", but that they follow one "weak form" consistent with decisions that must be taken in condition of uncertainty. This analysis will allow us to construct more realistic models of financial markets considering not only their conditions of normality as well as the circumstances that explain their instability and crises.

KEYWORDS: Efficient markets; financial markets.

JEL Classification: G3.

${ }^{1}$ Este artigo é parte de pesquisa financiada pelo NPP - Núcleo de Pesquisas e Publicações da FGVEAESP

* Professor do Departamento de Economia da Escola de Administração e Economia de São Paulo da Fundação Getúlio Vargas - EAESP, São Paulo/SP, Brasil. E0mail: lalima@fgvsp.br 


\section{INTRODUÇÃO}

O capitalismo, como um sistema econômico de decisões descentralizadas, caracteriza-se por uma grande opacidade em relação à sua dinâmica futura, devendo em função disto procurar alternativas capazes de reduzir o efeito de tal característica. Esta necessidade se mostra urgente, principalmente nos momentos em que são tomadas as decisões de investimento, de modo a não se desperdiçar o capital investido em projetos improdutivos ou não inteiramente adequados aos desejos dos consumidores. Segundo a chamada hipótese dos mercados eficientes, de agora em diante HME, tal missão seria realizada pelo mercado acionário, ${ }^{1}$ o que lhe conferiria sua utilidade social. Seriam tais mercados considerados "como o ator coletivo que centraliza as informações, as interpreta e produz uma estimativa pertinente dos valores fundamentais. A teoria da eficiência vai mesmo mais longe ao dizer que, através de tais mercados, são engendradas as melhores estimativas possíveis, dada a informação disponível, em um mundo mercantil dominado pela incerteza; estas atividades de informação, previsão e cálculo tornariam essenciais esses mercados" (Orlean, 1999: 21-2).

Tais estimativas seriam possíveis na medida em que os investidores considerassem para suas decisões acionárias um conjunto de parâmetros envolvendo a organização produtiva, a gestão, a situação da concorrência, a evolução das técnicas e a conjuntura macroeconômica, considerados os fundamentos dos quais depende $o$ valor básico das ações. Ou seja, supõe-se que as antecipações dos agentes estão voltadas fundamentalmente para a "economia real". Assim, se o preço de um título é superior ao valor básico calculado pelo investidor, seu preço deve cair e vice-versa.

Tal estratégia, identificada como "fundamentalista”, se apóia sobre a visão walrasiana convencional, identificada pela lei da oferta e procura:

"Ela nos faz ver os investidores agindo de forma isolada, calculando da melhor forma possível, a partir de suas informações, os valores fundamentais e determinando a estrutura de seus portfólios em função dos preços atuais de mercado. Para estes agentes, o que conta são os dados fundamentais e não o comportamento dos demais agentes. Suas antecipações são determinadas por uma realidade exterior ao mercado, ou seja, a rentabilidade real de seus investimentos" (idem: 24).

Tendo em vista tais considerações, pretende-se discutir neste trabalho: a evolução da HME; as contestações a tal hipótese; uma alternativa para a análise dos mercados financeiros, especialmente o mercado acionário; como certas características de tais mercados podem estender-se para os demais mercados de ativos e suas implicações; e finalmente, se chamará a atenção para que, dadas as características intrínsecas dos mercados financeiros, eles dificilmente poderão constituir-se em um guia eficiente no processo de alocação do capital produtivo. 


\section{A EVOLUÇÃO DO CONCEITO DE MERCADOS EFICIENTES}

Eugene Fama (1970) distinguiu três tipos de eficiência: a fraca, a semiforte e a forte. A fraca estabelece que a tendência dos preços passados não permite a antecipação dos preços futuros. A semiforte estabelece que os preços dos títulos se ajustam quase imediatamente às informações significativas (lucros das empresas, distribuição de dividendos etc.). $\mathrm{E}$ a forma forte assinala que não existe algo, como um grupo especial de investidores, que goze de acesso privilegiado às informações que não se reflitam imediatamente nos preços de mercado.

Conseqüência destas hipóteses é que o preço de mercado de uma ação ou de um outro título deve corresponder ao seu "preço correto" ou teórico, de tal maneira que a HME estabelece que o que determina tais preços é o seu risco. Assim, no modelo CAPM desenvolvido por Sharpe, Lintner e Black, também conhecido por SLB, o risco é definido pela volatilidade dos retornos esperados de um ativo, ou seja, sua variância em torno de uma norma. Esta volatilidade é determinada pela comparação com algum padrão, normalmente um investimento usualmente "sem risco" como um título do tesouro. O risco não deve ser considerado, como de hábito, uma possibilidade de perda, mas como a probabilidade de um desvio de um certo retorno esperado, ou seja, o risco característico de um título é identificado na literatura pelo seu .

De acordo com o modelo CAPM, uma forma de se reduzir o risco incorrido pelo investidor seria a diversificação de seu portfólio, de tal maneira a reduzir o risco de perda decorrente de modificações no preço de uma ação específica. Tal diversificação, no entanto, não permite a eliminação do risco de uma ação que decorre de oscilações do mercado acionário como um todo. A este tipo de risco não assegurável é que se identifica. Uma ação com $\beta=1,0$ tende a se mover em linha geral com o mercado; porém uma ação com $\beta=1,5$ tende a se mover $1,5 \%$ para cima ou para baixo para cada variação de $1,0 \%$ no mercado. Uma ação com $\beta=0$ não terá risco. Disto decorre que a taxa de retorno de um investimento deveria ser composto da remuneração de uma aplicação sem risco, mais o seu $\beta$. Quanto maior o maior o retorno requerido.

$\mathrm{Na}$ sua formulação mais moderna, os teóricos dos mercados eficientes afirmam que a tendência dos preços é identificada com um "random walk", significando que tais preços não podem ser previstos desde que sua variação média, isto é, sua oscilação em termos de um valor fundamental, não sugere um padrão diferente de variações puramente aleatórias. Assim, se isto for verdade, isto é, "se a informação já está capitalizada no preço de uma ação, conhecê-la não fará de você um melhor investidor. Atirar dardos nas páginas financeiras do New York Times é uma estratégia de investimentos tão boa, como tentar acumular todas as informações disponíveis sobre qualquer ação, mesmo porque aquela não custa nada, enquanto a coleta de informações envolve um preço" (Thurow, 1984: 151).

Assim, dentro de cada classe de risco, existe uma loteria com uma distribuição aleatória não normal "na qual os indivíduos apostam em investimentos individuais com iguais valores esperados (com chance igual de ganhar), mas que apresentarão 
diferentes retornos ex post. Como em qualquer loteria, existe um valor médio esperado para qualquer dólar investido, mas também, como em qualquer loteria, alguém vencerá e alguém perderá. Além disso, os grandes vencedores não terão como contrapartida grandes perdedores" (idem: 151).

Apesar de Fama ter mostrado que as condições de funcionamento dos mercados financeiros, acima descritos, envolvem condições muitos restritivas - a) não haver custo de transações no mercado de título; b) as informações devem ser disseminadas igualmente entre todos os participantes; c) todos os participantes desenvolvem interpretações similares de tais informações — nos anos 60, 70 e 80 praticamente não houve contestações empíricas ao funcionamento desses mercados e mesmo algumas anomalias já identificadas nos anos 60 não foram consideradas suficientes para falsificar a hipótese dos mercados eficientes. Assim, a presença de correlação serial no preço das ações, em períodos de tempo muito curtos, por exemplo, de um dia para outro, foi considerada muito restrita para se transformar em lucros; profissionais que negociam com pequenas comissões não poderiam extrair vantagens dessas pequenas tendências, "além disso, se mostrou que grandes variações de preços são provavelmente seguidas por outras grandes variações, embora não houvesse padrão capaz de prever o sinal da variação; uma grande variação para uma ação em um dia seria provavelmente seguida por uma grande mudança no dia seguinte, mas esta mudança poderia ser positiva ou negativa. É desnecessário dizer-se que tal descoberta não seria muito útil para os especuladores" (Henwood, 1997: 165).

De outro lado, durante os anos 60, procurou-se observar o efeito de anúncios de mudanças de dividendos no lançamento de novas ações para testar a hipótese semiforte dos mercados efetivos. Verificou-se que esta hipótese não poderia ser testada devido ao fato de as compras e vendas de ações acontecerem antes de as informações tornarem-se públicas, o que significava que uma boa parte dos operadores era presciente ou grandemente bem informada. Nos anos 70, a hipótese forte não passou por outros testes: alguns estudos mostraram que "insiders", executivos de nível superior e membros de conselhos de corporações tinham condições de vender e comprar no tempo hábil para obtenção de lucros elevados.

Apesar dessas constatações a HME não foi abandonada, com base no argumento de que os agentes, por serem uma pequena classe de investidores, não teriam condições de bater o mercado, apesar de obterem lucros pontuais.

Nos anos 90, a HME tornou-se mais flexível para se adaptar a novos testes críticos. A idéia passa a ser a de se justificar tal hipótese, desde que as informações contidas nos preços reflitam um certo consenso dos operadores, independente de o preço que dele resulte corresponder ou não a uma informação realista. Por exemplo, os investidores superavaliaram as empresas americanas no fim da década de 70. Houve um consenso, mas o consenso estava errado; isto, porém, não invalidaria a hipótese, segundo seus defensores, pois na medida em que tal informação fosse do conhecimento de todos os operadores, as oscilações de preço se dariam em torno de um preço médio estabelecendo-se uma "convenção de normalidade" tal como definida por Keynes (1936). 


\section{ALGUMAS CONTESTAÇÕES À HME}

Vinte anos após a publicação de seu artigo de 1970, Eugene Fama (1991) apresentou uma nova avaliação da HME, definindo-a "pela simples afirmação de que ela implica em uma situação em que os preços dos títulos revelam inteiramente todas as informações disponíveis” (p. 1.575)

Analisando as principais pesquisas empíricas desenvolvidas neste período, $\mathrm{Fa}$ ma reconhece que "os novos trabalhos concluem que os retornos podem ser previstos a partir de retornos passados dos dividendos e de variáveis monetárias, com diferentes estruturas temporais. Os novos testes rejeitam a antiga visão dos retornos constantes, implícita na visão dos mercados eficientes, que pareciam funcionar adequadamente, nos trabalhos iniciais" (idem: 1.577)

No artigo de 1991, Fama deixa de lado a antiga visão de formas fracas, semifortes e fortes da HME, para se basear apenas no problema da previsibilidade dos retornos; assim, ao invés de considerar como variáveis preditivas somente os retornos passados, passa a incluir nos testes de previsibilidade variáveis como rentabilidade dos dividendos e taxas de juro. Desde que eficiência e preços de equilíbrio são inseparáveis, tais trabalhos incluem também testes de preços de ativos e de anomalias.

Nas páginas seguintes serão considerados alguns desses trabalhos, incluindo basicamente os analisados por Fama, bem como os baseados em hipóteses alternativas de racionalidade como os de De Bondt e Thaler e os testes de volatilidade, como os de Shiller e Le Roy e Porter.

Assim, Fama (1991) observa que Lo e Mckinlay (1988), trabalhando com informações do Nyse e Amex, puderam estabelecer de maneira precisa a existência de autocorrelação nos retornos diários e semanais. Estabeleceram "que o retorno em portfólio das ações do Nyse, agrupadas de acordo com o tamanho (preços das ações vezes o seu número), mostram confiável autocorrelação positiva" (Fama, 1991: 1.578). Além disso, grande número de estudos realizados nos anos 70 e 80 concluiu que ações com baixas relações preço/lucro (cheap stoks) tiveram uma melhor performance que ações que eram consideradas "caras". Pesquisa desenvolvida por Fama e French (1989) mostrou que é vantajoso adquirir uma ação quando as taxas de juro de longo prazo estão bem acima das de curto prazo, e quando o "gap" entre a taxa de juro e o retorno sobre as ações é grande. Daí observarem que "a persistência de condições difíceis na economia pode assinalar queda na riqueza e maior risco no retorno dos títulos; ambos os fatores podendo, no entanto, assinalar aumento nos retornos esperados. Além disso, se se antecipa que os maus tempos são apenas temporários, os retornos esperados podem ser elevados porque os consumidores procuram antecipar o consumo do futuro para o presente" (Fama, 1991: 1.585).

Em 1992, em novo artigo, Fama e French submeteram o modelo de avaliação a uma crítica rigorosa ao mostrar que o tamanho da firma e a razão entre o valor de mercado e o valor contábil da empresa preveriam melhor o retorno de uma ação que . Neste contexto apresentou-se uma alternativa analítica ao modelo $\beta$ (Chen, 
Roll e Ross, 1986). De acordo com ela, melhores previsores do retorno futuro são a taxa de crescimento da produção industrial (com retornos futuros elevados quando a produção industrial fosse elevada e vice-versa), e a diferença entre a taxa de juro em títulos das empresas de avaliação baixa e a taxa de títulos governamentais de longo prazo (com retornos futuros elevados quando o spread é grande). Tais hipóteses justificam previsibilidade dos retornos futuros das ações, enfraquecendo assim a HME.

A literatura inicial apresentada por Fama (1970) não considerou autocorrelações diárias e semanais no retorno das ações como sendo importantes evidências contra a HME, apontando que mesmo quando as correlações entre retornos se desviam claramente de zero, estão próximas a zero e portanto são insignificantes. Tal conclusão, no entanto, foi criticada por Shiller (1984) e Summers (1986). Eles consideraram modelos em que os preços das ações podem apresentar grandes oscilações afastando-se dos valores fundamentais (bolhas irracionais), mas que em um horizonte de tempo reduzido apresentam autocorrelação reduzida. Em sua análise, Shiller e Summers mostram que os mercados são altamente ineficientes, mas de uma maneira que não é identificada nos testes que consideram um horizonte de tempo reduzido.

Este ponto pode ser esclarecido: suponha que o valor fundamental de uma ação é constante e "que a média não condicionada do seu preço é seu valor fundamental. Suponha que os seus preços diários são uma regressão de primeira ordem com inclinação próxima a 1 . Todas as variações de preços resultam de longas oscilações em relação ao seu valor fundamental. No curto prazo, uma auto-regressão de primeira ordem com inclinação próxima a 1 significa que os preços pareçam um random walk e os retornos tenham uma baixa correlação. Assim, nos testes de curtos períodos de tempo, todo os preços parecem ser permanentes quando o valor fundamental é constante, e que todos os desvios dos preços dos fundamentos são temporários"(Fama, 1991: 1.580). ${ }^{2}$

Além dos testes de previsão do retorno, a avaliação crítica da HME se estendeu ao problema da volatilidade. Shiller (1981), baseando-se na hipótese de que se um mercado é eficiente, a variação do preço de um ativo deve estar limitada por um valor teórico que não depende senão da variabilidade dos determinantes fundamentais do preço, comparou graficamente o valor dos preços das ações com seu "verdadeiro" valor, ou seja, o valor que um mercado perfeitamente racional teria estabelecido para essas ações, no período de 1871 a 1979. A linha obtida para os dividendos é perfeitamente estável, mesmo durante a Grande Depressão, mas a linha representando o preço das ações "ziguezagueia” de tal maneira que permane-

\footnotetext{
${ }^{2}$ É verdade que Fama e French (1988) procuram enfraquecer tal conclusão, porém reconheceram que este é um problema que aparece nas séries de tempo de eficiência de mercado, sem solução clara, isto é, não se podem distinguir (ex ante) bolhas irracionais de retornos esperados variando no tempo (idem: 1581).
} 
ce em pontos extremos de sub ou supervalorização por anos, e mesmo ao longo de décadas.

Ainda Le Roy e Porter (1981) desenvolveram um teste de volatilidade que segundo eles teria uma grande vantagem em relação aos testes de retorno apresentados até então. Os testes de Le Roy e Porter (1981) exploraram a demonstração de Samuelson (1965) de que no contexto do mercado de ações, a relação de valor presente é equivalente (sujeito a uma suposição de convergência) à hipótese nula testada nos testes de retorno. Tal relação estabelece que o preço presente da ação é o melhor previsor do valor futuro descontado e dos dividendos, vistos como o preço racional ex post. De maneira mais precisa, "o valor presente da relação estabelece que o preço corrente atual corresponde à esperança matemática dos preços racionais ex post, dada toda informação disponível para os investidores" (Le Roy e Steigerwald, 1995: 411-2). Ou seja,

$$
P_{t}=\mathrm{E}\left(P_{t}^{*} / I_{t i}\right)
$$

sendo

$$
P_{t}^{*}=\sum_{i=t}^{\alpha}\left(\frac{1}{i+r}\right) d_{t+i}
$$

sendo $P_{t}^{*}$ a previsão perfeita do valor descontado dos dividendos futuros [d], sendo dada uma taxa de desconto $r$, e os preços correntes das ações $P_{t}$.

De acordo com a visão convencional $P_{t}^{*}$ tem uma variância que corresponde a uma variância dos dividendos. Esta variância no entanto deveria ser maior que a variância de $P_{t}$, pois esta é uma previsão que é feita a partir de $P_{t}^{*}$, ou seja, em princípio

$$
\mathrm{V}\left(P_{t}\right) \mathrm{V}\left(P_{t}^{*}\right)
$$

De acordo com a teoria, a variância do valor esperado condicional de uma variável aleatória $V P_{t}$ é menor que a variância da variável aleatória $V P_{t}^{*}$. Ora, Le Roy e Porter e Shiller estabeleceram em seus testes empíricos que tal condição era violada. Os preços das ações são muito voláteis para serem explicados por mudanças nos dividendos, argumentando que seu testes teriam um poder maior que os testes de retorno. (Para uma discussão detalhada deste argumento, ver Sheffrin, 1986: 143-6.)

As constatações dessa volatilidade excessiva, quando comparada com a variação dos dividendos, deram lugar a várias interpretações, sendo a dominante a de Shiller (1981), de que preços das ações são grandemente influenciados pela moda e/ou ondas de otimismo e pessimismo, tal como descrito pela psicologia convencional dos mercados (p. 297).

Estas hipóteses levaram ao desenvolvimento de explicações baseadas em tipos específicos de comportamento dos agentes que povoam os mercados financeiros e que fogem radicalmente da HME. De maneira mais precisa, os agentes tendem a superestimar novas informações antes que ponderá-las em um contexto temporal.

Nesta linha, De Bondt e Thaler (1985) utilizaram tal hipótese para prever os preços das ações: um portfólio composto de um grande número de "ações perdedoras", isto é, batidas pelo mercado, teve um comportamento melhor que a média 
das ações nos três anos seguintes. Ou seja, as perdas iniciais foram o resultado de reações exageradas (overreactions), que se corrigiram, porém somente após a passagem de um razoável período de tempo. Para explicar tal comportamento fez-se a hipótese da existência dos chamados "noisy traders", ou seja, agentes quase-racionais. De Long, Shleiffer, Summers e Waldman mostraram que, em algumas circunstâncias, os "noisy traders" podem ganhar mais que os agentes racionais; "uma vez que assumem não intencionalmente mais riscos, os "noisy traders" têm uma menor utilidade esperada, mas uma maior riqueza" (De Bondt e Thaler, 1995: 387).

A existência de tais agentes explica também o processo chamado de "reversão da média": quando no curto prazo os preços alcançam valores muito maiores do que seria de se esperar racionalmente, a bolha se desfaz e os preços retornam para um valor fundamental. Fama e French (1988) identificaram este fenômeno num período de três anos para cada cinco. Analisando o comportamento das ações em um período de 60 anos (1926 a 1985) constataram que a reversão da média explica cerca de $35 \%$ do comportamento dos preços das ações. Embora a tendência para que isto aconteça seja maior para as ações de firmas menores, aconteceu também com ações mais importantes, em 17 grupos industriais.

Essas constatações reduziram bastante o ardor dos defensores da HME. Isto se pode verificar pela mudança da posição de Eugene Fama — que em 1970 considerava os mercados eficientes como realidades - para sua observação recente, ao considerar a HME apenas como "uma hipótese útil que permite superar os complexos problemas de decidir o que é razoável considerar-se como informações e custos de transação (...) cada leitor tem condições de julgar os cenários onde a eficiência de mercado é uma boa aproximação (...) (isto é, aqueles em que os desvios da versão extrema da hipótese da eficiência podem ser incluídos nas informações e custos de transação) daqueles (cenários) onde outro modelo constitui-se em uma melhor visão do mundo" (idem: 1.575).

\section{UMA ANÁLISE ALTERNATIVA DOS MERCADOS FINANCEIROS}

Uma das razões mais convincentes para a rejeição da HME são as freqüentes inovações no sistema financeiro. Quando uma inovação aparece é necessário um tempo razoável para identificar seu efeito nos preços dos ativos. Durante este período de transição, na medida em que mais agentes adotam a inovação, agentes que estão mais familiarizados com ela terão vantagem sobre os retardatários, obtendo lucros pela arbitragem entres os produtos novos e os antigos. Segundo as pesquisas de Fama e French (1988), até o período de um ano há uma autocorrelação positiva entre os lucros, ao passo que para períodos mais longos a autocorrelação torna-se negativa.

A interpretação dinâmica dessa constatação seria que os rendimentos iniciais elevados atraem novos adotantes para o processo de inovação, até que a competição faça desaparecer a vantagem informacional dos primeiros investidores. Tais 
condições incitam o lançamento de outras inovações tendo em vista a obtenção de novas vantagens informacionais, ou seja:

"Em períodos nem muito curtos nem muito longos, este processo envolve o fato de que um rendimento mais elevado que os rendimentos médios... terá uma probabilidade importante de ser seguido por um rendimento em baixa, pela dominação das forças concorrenciais. Em contrapartida, a pressão concorrencial aumenta a probabilidade de inovações que criam novos mercados, nos quais os rendimentos mais elevados podem ser, de novo, realizados. Suscitando aprendizagem, as inovações dão uma memória aos mercados, o que viola o postulado da eficiência" (Aglietta, 1995: 27).

Mesmo mercados que não exibam rendimentos correlacionados podem exibir volatilidades variáveis, de modo a criar essa memória; assim o conhecimento de uma volatilidade forte ou fraca no passado recente pode levar à antecipação de resultados diferentes a partir de um certo nível de volatilidade atual. A autocorrelação dessa volatilidade pode, portanto, informar a respeito das oscilações globais do mercado. Se a volatilidade é grande, o mercado tende a oscilar de maneira mais freqüente que no caso em que as variações de preços sejam independentes no tempo. Diante disto, se coloca a necessidade de analisar as condições reais que estão por trás desses fenômenos, como se fará a seguir.

A primeira grande simplificação da HME é de que os operadores são homogêneos, isto é, todos se baseiam em princípios comuns de racionalidade. Este pressuposto, no entanto, está bastante longe de ser realista, pois como observam Summers e Shleiffer (1990):

"Nossa abordagem se baseia em duas hipóteses. Em primeiro lugar, certos investidores não são totalmente racionais e sua demanda por ativos de risco é afetada por suas crenças ou sentimentos que não são inteiramente justificados por informações a respeito dos fundamentos. Em segundo lugar, a arbitragem definida como as decisões tomadas por investidores inteiramente racionais, não sujeitos a tais sentimentos, envolve risco e é, portanto, limitada. As duas hipóteses, em conjunto, implicam que mudanças nos sentimentos do investidor não são integralmente contrabalançadas pelos arbitradores e assim afetam os retornos dos títulos” (pp. 19-20).

A idéia da arbitragem é a de que há certos investidores, os arbitradores, que se movimentam rapidamente, toda vez que os títulos estejam sobre ou subvalorizados, de tal maneira a fazer com que os seus valores voltem a seus níveis "racionais", vendendo ou comprando esses títulos. Tais movimentos são efetivos se o agente está trabalhando com dois ativos similares e, portanto, substitutos. Por exemplo, se o ouro estiver sendo vendido a US\$ 350 a onça em Nova York e a US\$ 355 em Londres, o especulador imediatamente compraria ouro em Nova York e venderia em Londres. Tal arbitragem, no entanto, não seria possível, sem risco, se para um 
arbitrador todo o estoque de ações americanas está sobrevalorizado. Neste caso o que ele deve comprar e vender, para trazer os preços ao seu nível "normal”? E sobre o perigo de que as ações sobrevalorizadas possam se valorizar ainda mais antes de voltarem para o seu valor racional? Como se pode determinar qual o seu preço racional? E se os lucros estão para decolar, de tal maneira que o aparente valor irracional não é tão absurdo? E o que dizer se o "short seller" ${ }^{3}$ tem de garantir os dividendos para as ações vendidas "short"?

Assim, mesmo que o mercado esteja composto por arbitradores, há situações em que sua ação é limitada, como exemplificado acima. Porém, o mercado não está composto apenas por "espíritos racionais", mas está povoado por espíritos "não tão racionais", na concepção convencional, que são movidos por pseudos-informações (noise) e constituem os chamados "noisy traders". Ora, se estes operadores tomassem suas decisões baseadas nos seus próprios planos ou sentimentos, suas decisões seriam independentes e poderiam cancelar-se; mas em vez disso "o viés dos julgamentos que aflige os investidores ao processar as informações tende a ser o mesmo. Sujeitos de experimentações psicológicas tendem a cometer os mesmos erros, eles não cometem erros aleatórios; muitos destes erros persistentes são relevantes para os mercados financeiros. Por exemplo, sujeitos de experimentos tendem a ser superconfiantes, o que os faz assumirem maiores riscos. Os sujeitos de experimentos tendem a extrapolar séries temporais, o que os leva a perseguirem tendências passadas. Finalmente, ao realizarem inferências experimentais, tendem a desprezar evidências presentes e dar muito peso às novas informações" (Summers e Shleiffer: 23-4).

A evidência trazida por tais experimentos tem sido comprovada por questionários e outras enquetes no mercado financeiro. Shiller (1990) mostrou que a extrapolação é uma característica dos chamados "modelos populares". Ele constatou que os compradores de residências, bem como os investidores no crash de 1987, extrapolaram tendências de preços passados. A observação dos mercados tem apresentado suficientes evidências de que rumores (noises) determinam boa parte das decisões. Estas também tendem a acompanhar "gurus" como Joe Granville e previsões fornecidas pela Wall Street Week. Geralmente, os "gurus", que atraem grande número de seguidores, nunca admitem que obtêm "inside informations" mas, sim, que seguem modelos confiáveis de previsão. A chamada "análise técnica”, que se enquadra neste último tópico, tipicamente recomenda comprar mais ações quando o preço destas está se elevando (atravessam um teto) e vendê-las quando estão abaixo de um piso.

Summers e Shleiffer (1990) observam que os economistas convencionais tendem a desprezar o efeito desses comportamentos, pois admitem que os "noisy traders" tendem a perder dinheiro em favor dos "arbitradores", fazendo com isso que se reduza o seu efeito na demanda. Aqueles autores argumentam que isto não é evidente. Primeiro porque na média os "noisy traders" são mais agressivos que

3 “Short seller" é alguém que vende um título que não possui para entregar futuramente. 
os arbitradores, ou porque são superotimistas ou superconfiantes e assim assumem maiores riscos. "Se o risco é remunerado no mercado, os 'noisy traders' podem obter retornos esperados mais elevados, a despeito de terem comprado na alta e vendido na baixa na média. A remuneração do risco no mercado não precisa ser mesmo fundamental; pode ser o preço do risco de revenda decorrente da imprevisibilidade das opiniões futuras dos 'noisy traders'" (Summers e Shleiffer: 24-5).

A consequiência disto é que os efeitos de mudanças da demanda nos preços são maiores do que seriam se a maioria dos investidores seguisse os livros-texto de finanças e mantivessem passivamente o "portfólio de mercado", ou quando a capacidade de assumir riscos dos arbitradores fosse reduzida.

A importância dos investidores que tendem a extrapolar ou "caçar a tendência" também dever ser ressaltada. Alguns especuladores acreditam que se acompanharem a onda (band-wagon) serão capazes de bater os "noisy traders". Esta foi e tem sido a estratégia de George Soros. Assim, "as transações entre os investidores racionais dão lugar a padrões de preços do tipo bolha. A estratégia de 'feed back' é reforçada pela adesão à onda dos investidores racionais, o que leva a uma autocorrelação positiva dos retornos a curto prazo" (idem: 29).

Finalmente, deve-se acrescentar um terceiro grupo de operadores, que são os “seguradores de portfólio". São investidores institucionais que administram grandes fundos de poupança contratual, diversificando riscos pela aquisição de contratos de índices representativos do conjunto dos mercados. Procuram assegurar-se de que o valor de seu portfólio não caia abaixo de um mínimo predeterminado. Podem comprar opções de vendas sobre o portfólio (put options) para cobrir os contratos sobre índices, até o seu vencimento. Podem assim construir opções sintéticas combinando contratos sobre índices e títulos de dívida sem risco.

A análise acima chama atenção para a multiplicidade de comportamentos possíveis em situações em que há condições de incerteza não passíveis de serem submetidas a uma análise atuarial. Outra limitação da HME é não considerar surgimento de crenças que se auto-realizam, não necessariamente por estarem mais próximas dos fatos, mas, muitas vezes, porque se apresentam com maior antecedência, contagiam grande número de agentes, como sugerido pelo modelo de "path dependence", ou mesmo por ser uma estratégia dominante na visão de Schelling. A partir destas constatações se tentará a seguir construir a lógica das condições que podem levar à instabilidade financeira, cujo caso extremo seria um "crash" de mercado.

Consideremos inicialmente o comportamento dos "noisy traders" e dos "seguradores de portfólio", diante de certas tendências de preço. Tais agentes têm uma função de demanda de títulos que é crescente em relação aos preços. Os primeiros procuram identificar regimes dinâmicos a partir das tendências dos mercados. Quando identificam uma tendência altista ou baixista, acreditam que essa tendência persistirá e que geralmente, no momento em que as identificam, elas estão longe de reverter. Assim, é natural que comprem na alta e vendam quando identificam uma reversão. Para os segundos, sua posição em relação aos títulos, especificamente às ações, depende do $\Delta$ da opção, que é a sensibilidade da variação do 
preço da opção, em relação ao preço da ação correspondente. Ora, o $\Delta$ varia de uma maneira contínua e não linear com o preço da ação, de tal modo que a posição deve ser ajustada continuamente ao longo do tempo. Quando o preço das ações se eleva, o $\Delta$ diminui, de tal maneira que se torna necessário reduzir as posições "curtas" ", demandando-se imediatamente mais ações. Quando os preços das ações baixam, o $\Delta$ aumenta, de tal forma que é necessário aumentar as posições "curtas". Fica claro, assim, por que a demanda líquida dos seguradores de "portfólio" é uma função crescente e não linear dos preços das ações; quando o preço destas se eleva, por qualquer razão, essa tendência é ampliada pela demanda adicional dos "seguradores de portfólio"; quando o preço destas cai, a tendência de queda é ampliada pelas ofertas adicionais destes (cf. pp. 29 e 30).

Os "arbitradores" de outro lado seguem a racionalidade estrita em suas decisões, isto é, compram na baixa e vendem na alta, acreditando que existe um preço de atração ou um preço médio em torno do qual ocorre uma oscilação para cima e para baixo. Assim, se tais operadores fossem os únicos no mercado, e se houvesse realmente um preço normal, haveria sempre equilíbrio de mercado. Acontece, no entanto, que uma função de excesso de demanda líquida de mercado, ao se agregar os diferentes comportamentos em diferentes proporções, não será monótona em relação aos preços nem estável no tempo, pois combina componentes crescentes e decrescentes, lineares e não lineares em relação ao preço.

\section{Gráfico I: Equilíbrios múltiplos nos mercados de ações}

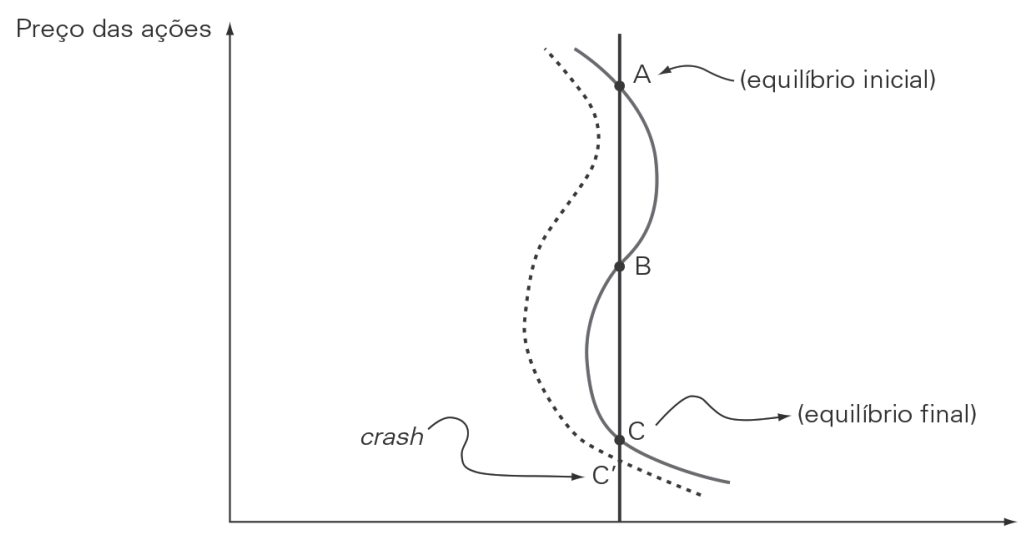

Consideremos no gráfico 1, acima, o modelo do mercado de ações desenvolvido por Genotte e Lelland (1990) e utilizado por Agglietta (1995), em que se baseia a análise seguinte. No gráfico acima há três equilíbrios, A e C estáveis e B instável.

\footnotetext{
${ }^{4}$ Alguém que tem uma posição curta ou "short" de ações, por exemplo, é alguém que se dispõe a entregar a um certo preço uma ação, por exemplo, não possuída por ele, na esperança de que na data da entrega o preço dessa ação tenha caído em relação ao presente.
} 
A instabilidade de B está ligada à volatilidade excessiva dos preços em relação ao preço que seria natural no mercado, e que é explicada pelos movimentos desestabilizadores tanto dos "noisy traders" como dos "seguradores de portfólio", que tendem a reforçar, como acima discutido, o movimento dos preços em um sentido ou outro. Sendo os mercados financeiros sempre mercados de liquidez, as demandas imprevistas de liquidez afetam as ofertas de ativos, além dos imprevistos que afetam as variáveis determinantes dos valores fundamentais das ações. Estas condições podem levar a um crash e a um regime dinâmico posterior. Tal situação pode ocorrer em função de um deslocamento de curva de excesso de demanda, que faz desaparecer o regime centrado em um equilíbrio inicial (A), estabelecendo a passagem do ponto A para o ponto C' (crash). O retorno da curva de excesso de demanda para a situação anterior não recupera o equilíbrio inicial. O preço evoluirá de C' para C, o qual é um equilíbrio estável.

Observa-se, aí, um processo endógeno que envolve instabilidade, que não pode ser explicada por fatores aleatórios exógenos. Tal processo é a imitação ou contágio. A possibilidade de imitar significa que o tamanho relativo dos grupos de agentes heterogêneos não é algo imutável. Certos operadores, que têm normalmente um tipo de comportamento, podem adotar o comportamento de outro grupo de operadores. Eles podem adotar estratégias mistas; um "arbitrador" pode achar conveniente ter em um certo momento o comportamento de um "noisy trader", por exemplo. Tais revisões de crenças são todavia racionais. Cada operador pode se preocupar em incorporar em suas decisões o julgamento dos outros para melhorar a adequação de suas antecipações.

No caso acima mencionado, um especulador racional adotando o comportamento dos "noisy trader" pode levar a uma descontinuidade no mercado ao reforçar os efeitos das decisões destes. Foi o que ocorreu com o "crash" do mercado de ações americano em outubro de 1987. Por razões que não serão consideradas agora, houve uma onda de ordens de vendas de tal maneira que caíram os preços das ações. Em tal circunstância, como se observou anteriormente, os "seguradores de portfólio" passaram a oferecer mais ações, procurando aumentar suas "posições curtas" (na expectativa que os preços caíssem ainda mais). Ora, este processo confirma o pessimismo daqueles que iniciaram o movimento de vendas das ações (boa parte deles "noisy traders"). De outro lado, os especuladores profissionais (arbitradores) ficam limitados em sua ação de compras das ações em baixa, devido à forte restrição de liquidez amplificada pelas vendas dos "seguradores de portfólio". A partir desse momento a baixa especulativa torna-se auto-realizadora, só podendo ser controlada por algo fora do mercado, por exemplo, um processo de salvamento mediante grande injeção de liquidez no mercado promovido pelo banco central.

\section{INSTABILIDADE FINANCEIRA E OS DEMAIS MERCADOS DE ATIVOS}

De acordo com a análise acima, pode-se verificar que a instabilidade financeira não é algo esporádico, mas faz parte da própria lógica dos sistemas financeiros. Ain- 
da, no tópico anterior, considerou-se, principalmente, a instabilidade enquanto localizada em bolsa, porém ela é mais geral, estendendo-se para os mercados de terrenos urbanos e imobiliários, onde é amplificada por fatores como a diminuição rápida de liquidez dos mercados secundários, imprevisibilidades das políticas governamentais etc. Além disso, o comportamento de tais mercados interfere grandemente na atividade produtiva da economia, tornando-se necessário considerar essas implicações.

A hipótese convencional é de que a otimização dos rendimentos financeiros articula-se de maneira harmoniosa com a atividade produtiva, em um modelo geral de mercados completos. Ocorre, no entanto, que os diferentes tipos de eficiência dos mercados financeiros - eficiência informacional, eficiência na avaliação dos valores fundamentais, eficiência na diversificação do risco e eficiência alocativa - não se compatibilizam necessariamente. Quando uma inovação financeira aumenta a eficácia informacional, não se pode inferir que a alocação do capital tenha melhorado. Isto é, quando novos mercados são criados, não se pode deduzir que os mercados tenham ficado mais completos (p.ex. a criação de um mercado futuro para um produto financeiro), pois os novos mercados podem criar novos riscos e desenvolver novas conexões entre os riscos já existentes, dando-lhes um caráter sistêmico.

De acordo com a visão convencional, para os mercados acionários guiarem de maneira adequada as decisões de investimento, seria necessário permitir aos acionistas exercer seu controle sobre as decisões dos executivos das empresas, o que iria requerer que aqueles obtivessem informações sobre o valor das empresas, isto é, o valor dos fundamentais, e sobre a capacidade de a empresa produzir lucros no futuro. A existência do mercado acionário, no entanto, dá aos acionistas a possibilidade de negociar a todo momento seus títulos nos mercados secundários, o que desliga os acionistas da análise dos fundamentais das empresas. Na realidade, os acionistas não têm nem a motivação nem os meios de realizar avaliações próprias da rentabilidade interna dos investimentos escolhidos pelos dirigentes. Eles se remetem inteiramente às bolsas. Desta forma, se submetem às opiniões coletivas da comunidade financeira que influenciam o total dos preços das ações, mesmo quando as variações destas nada têm a ver com a empresa em questão e não têm, portanto, condições de estabelecer informações adequadas e eficazes para as tomadas de decisão.

Aliás, esta constatação já havia sido expressa por Keynes (1936) ao observar que "as bolsas de valores reavaliam todos os dias seus investimentos e estas reavaliações proporcionam oportunidades freqüentes a cada indivíduo, embora isto não ocorra para a comunidade como um todo, de rever suas aplicações. É como se um agricultor, tendo examinado seu barômetro após o café da manhã, pudesse retirar seu capital da atividade agrícola entre dez e onze da manhã para reconsiderar se deveria investi-lo mais tarde... Assim, certas categorias de investimento são reguladas pelas expectativas médias dos que negociam nas bolsas, tal como se manifestam nos preços das ações, em vez das expectativas genuínas do empresário profissional” (p. 126).

De outro lado, a liberalização financeira recente afetou de maneira clara a forma de financiamento externo adequado das empresas, ao permitir o surgimento de inovações como títulos de crédito negociáveis, títulos de alto risco (como os 
junkbonds) e títulos híbridos compostos de créditos e fundos próprios (ações preferenciais e obrigações conversíveis), ou ainda títulos garantidos sobre ativos patrimoniais (asset-based financing). Criou novas possibilidades de financiamento externo, simultaneamente com uma redução do custo da intermediação financeira. Estes fatos, juntamente com o aumento da importância da poupança institucional, contribuíram, ainda mais, para que formas de decisões desligadas dos fundamentos prevalecessem nos mercados contemporâneos.

\section{CONCLUSÃO}

As tendências discutidas ao longo deste artigo mostram a precariedade da hipótese mencionada inicialmente sobre as funções dos mercados financeiros como um mecanismo adequado de orientação para o processo de alocação do investimento produtivo. Keynes já havia observado "que os investimentos baseados nas previsões autênticas de longo prazo são hoje tão difíceis que mal podem ser postos em prática. Os que tentarem fazê-lo poderão estar certos de passar dias de trabalho muito intenso e correr riscos muito maiores que os que tentam adivinhar as reações do público melhor que o próprio público, e, dada igual inteligência, podem cometer erros muito mais desastrosos" (1936: 130).

Se o investidor que insiste em decidir considerando os "valores fundamentais" dos títulos, mesmo que isto contrarie as tendências presentes do mercado, "obtiver êxito isto apenas confirmará a crença geral na sua temeridade; se, no final das contas, sofre reveses momentâneos, poucos serão os que dele se compadecerão. A sabedoria universal indica ser melhor para a reputação fracassar junto com o mercado do que vencer contra ele" (idem: 30 ).

Nestas condições as inovações financeiras se desenvolverão sempre para atender cada vez mais a demanda por liquidez e menor risco, originadas cada vez mais dos gestores de fundos públicos, dando lugar a uma dinâmica de preços que afasta cada vez mais os preços de mercado de seus fundamentos, gerando uma volatilidade de preços que tem pouco a ver com as oscilações próprias de um mercado hipoteticamente racional. A partir destas considerações, não é de se espantar que se constituam "novas formas de racionalidade" cada vez mais distantes da concepção clássica ou convencional de racionalidade.

\section{REFERÊNCIAS BIBLIOGRÁGICAS}

AGLIETTA, M. (1995) Macroeconomie Financière, Paris Editions La Decouverte.

CHEN, N., R. ROLL e S. ROSS (1986) "Economic Forces and Stock Market", Journal of Business, 59: 383-403.

DE BONDT, W. e R. THALER (1985) "Does the Stock Markets Overreact", Journal of Finance, 40: 793-805.

DE BONDT, W. e R. THALER (1995) “Financial Decision Making in Markets and Firms: A Behaviour Perspective”, em R. Jarrow et al. (eds.), Handbook in OR e MS, Elsevier, Amsterdam. 
FAMA, E. (1970) “Efficient Capital Markets: A Review of Theory and Empirical Work”, Journal of Finance, vol. 25, $\mathrm{n}^{\circ}$ 2: 383-417

FAMA, E. (1991) "Efficient Capital Markets II", Journal of Finance, 46: 1.575-1.617.

FAMA, E. e FRENCH, K. (1988) "Permanent and Temporary Components of Stock Prices", Journal of Political Economy, 96: 301-325.

FAMA, E e K. FRENCH (1989) "Business Conditions and Expected Returns on Stocks and Bonds", Journal of Financial Economics, 25: 23-49

FLOOD, R. P. e HODRICK,R.J. (1990) “On Testing for Speculative Bubbles”, Journal of Economic Perspectives, vol. 4, $\mathrm{n}^{\circ}$ 2, Spring: 85-101.

GENOTTE G. e LELLAND, H. (1990) "Market Liquidity, hedging and crashes", American Economic Review, dezembro.

KEYNES, J. M. (1936) A Teoria Geral do Emprego, do Juro e do Dinheiro. Tradução Mario R. da Cruz. São Paulo, Atlas.

KEYNES, J. M. (1936) The general theory of employment, interest and money, London, The McMillan Press.

LE ROY, F. e D. STEIGERWALD (1995) “Volatility”, em R. Jarrow et al. (eds.), Handbook in OR e MS, Elsevier, Amsterdam.

LE ROY, S. F. e R. PORTER (1981) “The Present Value Relation: Teste Implied Variance Bounds”, Econometrica, 49: 555-574.

LO, Andrew e A. Croig MCKINLAY (1988) "Stock Market Prices do Not Follow Random Wolks:

Evidence From A Simple Specification Test”, Review of Financial Studies, 1: 41-66.

ORLEAN, A. (1999) Le Pouvoir de la Finance, Paris, Editions Odile Jacob.

SAMUELSON, P. A. (1965) e "Proof that properly anticipated prices fluctuate randomly", Manage Rev., 6: 41-49.

SHEFFRIN, S. M. (1986) Rational Expectations, Cambridge, Cambridge University Press.

SHILLER, R. J. (1981) "Do Stock prices move too much to be justified by subsequent changes in dividends", American Economic Review, vol. 71, $\mathrm{n}^{\circ}$ 3, junho.

SHILLER, R. J. (1984) “Stock Prices and Scoail Dynamics”, Brooking Pappers on Economic Activity, 2: 457-510.

SHILlER, R. J. (1990) “Speculative Prices and Popular Models", Journal of Economic Perspectives, vol. 4, n 2, Spring: 55-65.

SUMMERS, L. H. (1986) “Does Stock Markets Rationally Reflect Fundamental Values”, Journal of Finance, 41: 591-600.

SUMMERS, L. H. e SHLEIFFER, A.(1990), “The Noisy Trade Approach to Finance”, Journal of Economic Perspectives, vol. 4, $\mathrm{n}^{\circ}$ 2, Spring: 19-33.

THUROW, L. (1984) Dangerous Currents: The State of Economics, New York, Vintage Books. 